Article

\title{
Noisiness of the Surfaces on Low-Speed Roads
}

\author{
Wladyslaw Gardziejczyk *, Pawel Gierasimiuk and Marek Motylewicz \\ Division of Road Engineering, Faculty of Civil and Environmental Engineering, Bialystok University \\ of Technology, Wiejska St. 45E, 15-351 Bialystok, Poland; p.gierasimiuk@pb.edu.pl (P.G.); \\ m.motylewicz@pb.edu.pl (M.M.) \\ * Correspondence: w.gardziejczyk@pb.edu.pl; Tel.: +48-85-746-96-03
}

Academic Editor: Elisabete Fraga de Freitas

Received: 29 February 2016; Accepted: 22 March 2016; Published: 25 March 2016

\begin{abstract}
Traffic noise is a particular threat to the environment in the vicinity of roads. The level of the noise is influenced by traffic density and traffic composition, as well as vehicle speed and the type of surface. The article presents the results of studies on tire/road noise from passing vehicles at a speed of 40-80 kph, carried out by using the statistical pass-by method (SPB), on seven surfaces with different characteristics. It has been shown that increasing the speed from $40 \mathrm{kph}$ to $50 \mathrm{kph}$ contributes to the increase in the maximum A-weighted sound pressure level by about $3 \mathrm{~dB}$, regardless of the type of surface. For larger differences in speed ( $30 \mathrm{kph}-40 \mathrm{kph}$ ) increase in noise levels reaches values about $10 \mathrm{~dB}$. In the case of higher speeds, this increase is slightly lower. In this article, special attention is paid to the noisiness from surfaces made of porous asphalt concrete (PAC), BBTM (thin asphalt layer), and stone mastic asphalt (SMA) with a maximum aggregate size of $8 \mathrm{~mm}$ and $5 \mathrm{~mm}$. It has also been proved that surfaces of porous asphalt concrete, within two years after the commissioning, significantly contribute to a reduction of the maximum level of noise in the streets and roads with lower speed of passing cars. Reduction of the maximum A-weighted sound pressure level of a statistical car traveling at $60 \mathrm{kph}$ reaches values of up to about $6 \mathrm{~dB}$, as compared with the SMA11. Along with the exploitation of the road, air voids in the low-noise surface becomes clogged and acoustic properties of the road decrease to a level similar to standard asphalt.
\end{abstract}

Keywords: road surface; tire/road noise; statistical pass-by (SPB) method

\section{Introduction}

The increasing traffic of vehicles requires different safeguards to reduce the noise level in the surrounding of road routes. Such safeguards most often include noise barriers and low-noise surfaces. In some countries, low-noise surfaces are recommended and quite commonly used on roads of higher speeds. In the literature, solutions with the application of single and double layer of porous asphalt and thin asphalt layer are discussed in great detail [1-3]. There are examples given for the reduction of noise by $5-6 \mathrm{~dB}$, and, in the case of the application of layers of poroelastic surfaces, up to about $10 \mathrm{~dB}[4,5]$. In many research centers, there are ongoing studies on the impact of the number and thickness of the layer, the addition of rubber granulate [6,7], the air void content, and macrotexture on the tire/road noise [8,9]. The analysis also includes the acoustic durability of upper layers of the road during the operation [10-14], as well as the influence of temperature and humidity of the surface on noise level [15-17]. Moreover, there are ongoing works on developing a systematic method of cleaning surfaces, allowing the preservation of the beneficial acoustic properties of surfaces with increased air void content, possibly in the long term.

Very often, construction of noise barriers as a solution against noise, in the case of the streets, and along roads of lesser importance, is not possible. One way to reduce the noise level then is applying low-noise surfaces. In some countries, wearing courses of porous asphalt are used on city 
streets and on low-speed roads [18,19]. At low vehicle speeds, however, these surfaces become clogged in a relatively short period of time, and, after a few years of operation, tire/ road noise level on such roads reaches values comparable to the noise level on the standard asphalt concrete (AC) and stone mastic asphalt (SMA) surfaces. Besides the loss of good acoustic properties of the surface, its structural durability decreases because of the high air void content in the wearing course. A better solution in such cases is applying thin layers of asphalt type BBTM (thin asphalt layer) and SMA, with a maximum aggregate size of $8 \mathrm{~mm}$ (SMA8) or even $5 \mathrm{~mm}$ (SMA5).

So far most of the streets of Polish cities and the roads of local importance were built with asphalt concrete. In recent years, wearing courses of reduced noisiness have been used in road construction. As the basic solutions, there are BBTM8, SMA8, SMA5 (the number means a maximum aggregate size in millimetre), and in some cases also single and double layer of porous asphalt. In historical parts of old cities or in old towns on the urban roads, paving stones and concrete block paving are used.

The aim of the article is to assess noisiness of different types of surface used for roads and streets servicing cars moving at lower speeds. Additionally, there is an assessment on the effect of increase in the speed of cars, clogging, and local defects in the wearing course of porous asphalt on the increase in the level of tire/road noise.

\section{Experiments}

The study covered seven road sections of the following types of surface (Figure 1):

- $\quad$ stone mastic asphalt with a maximum aggregate size $11 \mathrm{~mm}$ (SMA11), 8 mm (SMA8), and $5 \mathrm{~mm}$ (SMA5);

- $\quad$ single layer of porous asphalt with a maximum aggregate size of $8 \mathrm{~mm}$ (PAC8);

- $\quad$ two layers of porous asphalt with a maximum aggregate size in the top layer $8 \mathrm{~mm}$ and the lower layer $16 \mathrm{~mm}(\mathrm{DPAC} 8+16)$;

- $\quad$ paving (PS: paving stones, CBP: concrete block paving).

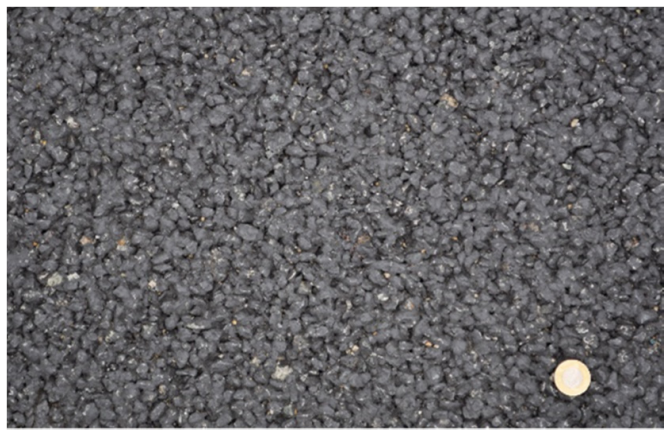

(a)

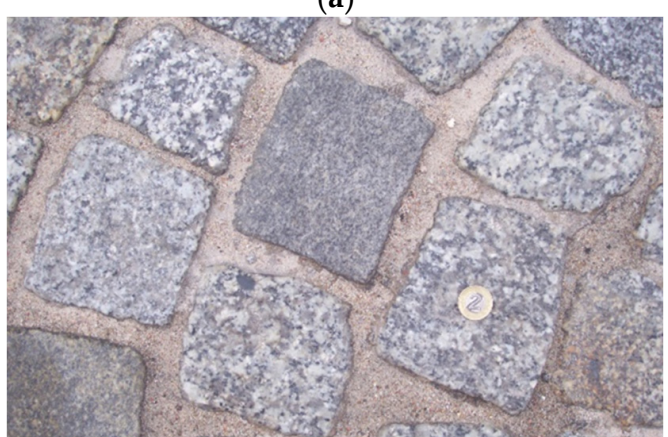

(c)

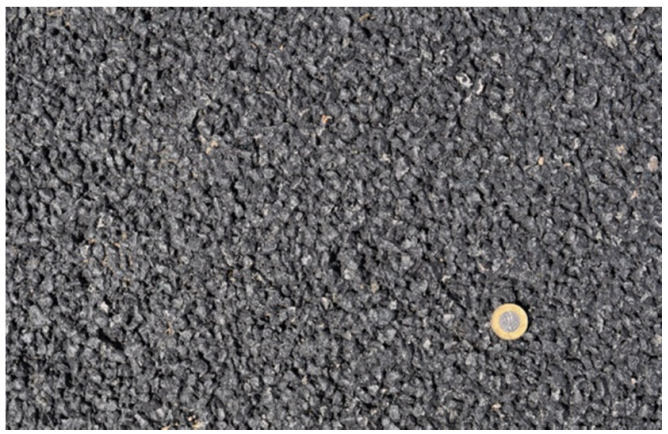

(b)

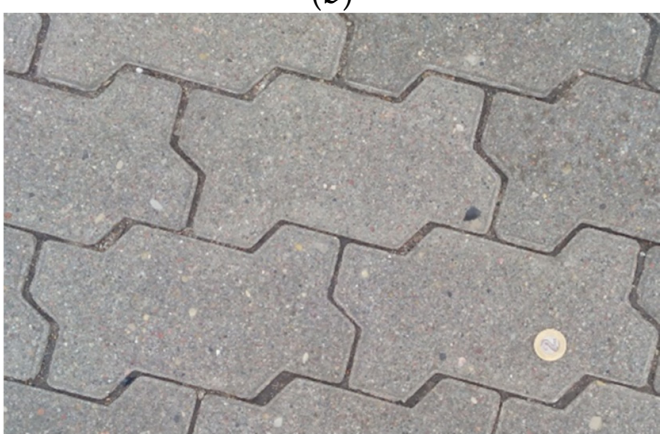

(d)

Figure 1. Cont. 


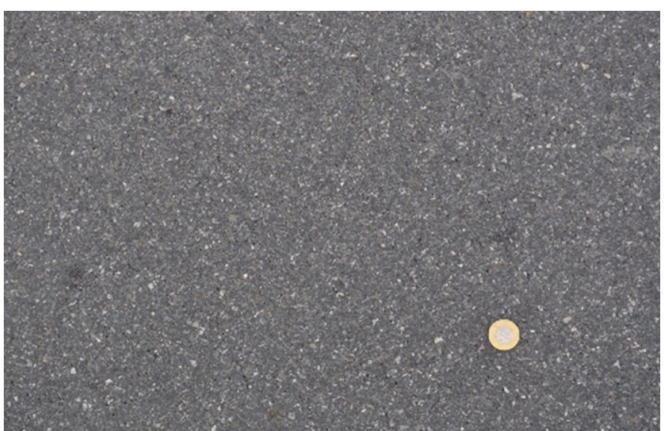

(e)

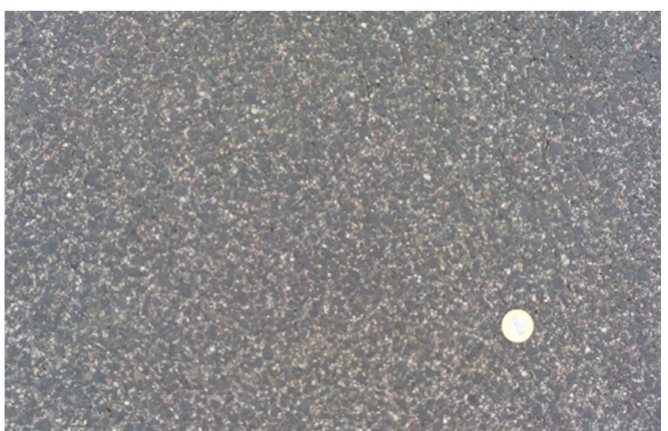

(f)

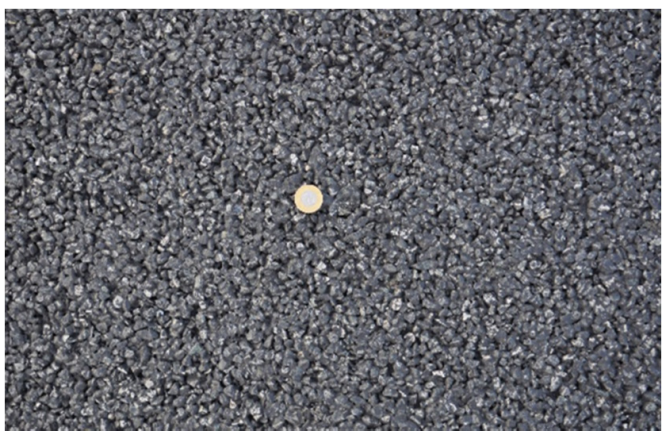

(g)

Figure 1. Tested road surfaces: (a) PAC8; (b) DPA8+16; (c) PS-paving stones; (d) CBP-concrete block paving; (e) SMA5; (f) SMA8; (g) SMA11.

The test sections were located on the streets and on roads of lower traffic speed. Due to the small share of multiple-axle heavy vehicles in the traffic on the streets of urban area and local roads only the maximum A-weighted sound pressure levels from cars passing at speeds from 40 to $80 \mathrm{kph}$ were analyzed. The measurements on the tested surfaces made with SMA11, SMA8, SMA5, PAC8, and DPAC $8+16$ were conducted in the first year of their operation. Additionally, further measurements were carried out on the PAC 8 surface after two and then four years of its exploitation. The paving surfaces remained in good state during all of the tests.

The evaluation of the impact of the type of road surface and the speed of passing vehicles on the noise level on the test sections was based on the assumptions of the statistical pass-by method (SPB) [20]. Measurements were carried out at a distance of $7.5 \mathrm{~m}$ from the axis of the lane, and at a height of $1.2 \mathrm{~m}$ in relation to the road surface, in the same weather conditions on all test sections. Due to difficulties in the recording of measurements in built-up areas, on certain sections the results could not cover 100 cars.

\section{Analysis of the Results}

\subsection{Results}

Figure 2 presents a comparison of results of noise levels tested on seven road surfaces as a logarithmic representation of speed.

Based upon the results of measurements, it was possible to determine regression dependencies allowing the calculation of the maximum A-weighted sound pressure level $\left(L_{\mathrm{Amax}(1)}\right)$ from the passing of a statistical car, at the assumed speed, according to Equation (1):

$$
L_{\text {Amax (1) }}(V)=A+B \cdot \log \left(V / V_{o}\right)
$$

where $L_{\mathrm{Amax}(1)}$ is the maximum A-weighted sound pressure level (category 1 -car) in $\mathrm{dB} ; A$ and $B$ are the coefficients of regression; $V$ is the speed, $\mathrm{kph}$; and $V_{o}=1 \mathrm{kph}$. 


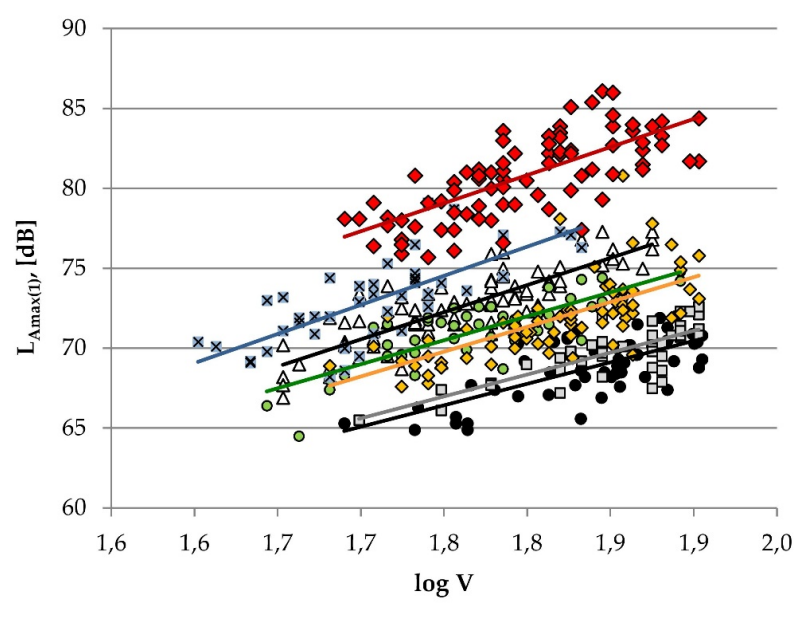

- PAC8 $\square$ DPAC8+16 $\triangle$ SMA11 $\circ$ SMA8 $\diamond \mathrm{SMA5} \times \mathrm{CBP} \diamond \mathrm{PS}$

Figure 2. Comparison of the results of SPB measurements on seven surfaces.

Table 1 compiles the average speed of tested vehicles $(V)$ with standard deviations $(s)$, the coefficients of regression $(A$ and $B)$, the correlation coefficients $(R)$, the maximum A-weighted sound pressure levels $\left(L_{\mathrm{Amax}(1)}\right)$ from a statistical car passing at $60 \mathrm{kph}$, and accuracy measures ( $95 \%$ confidence interval-95\% CI). As a conclusion of the results of the measurements, $60 \mathrm{kph}$ was adopted in the analysis as the reference speed for the test surfaces.

Table 1. Statistical information related to data SPB measurements.

\begin{tabular}{cccccccc}
\hline Surface & $\boldsymbol{V}, \mathbf{k p h}$ & $\boldsymbol{s}, \mathbf{k p h}$ & $\boldsymbol{A}$ & $\boldsymbol{B}$ & $\boldsymbol{R}$ & $\boldsymbol{L}_{\text {Amax } \mathbf{( 1 )}}(\mathbf{6 0}) \mathbf{, d B}$ & $\mathbf{9 5 \%} \mathbf{C I}, \mathbf{d B}$ \\
\hline PAC8 & 69.3 & 7.54 & 19.36 & 26.89 & 0.71 & 67.2 & 0.60 \\
DPAC8+16 & 71.6 & 7.19 & 18.91 & 27.46 & 0.77 & 67.7 & 0.60 \\
SMA5 & 66.2 & 7.69 & 15.48 & 31.03 & 0.66 & 70.7 & 0.55 \\
SMA8 & 59.7 & 8.10 & 17.94 & 30.03 & 0.82 & 71.3 & 0.40 \\
SMA11 & 58.4 & 7.79 & 12.85 & 33.94 & 0.84 & 73.2 & 0.30 \\
CBP & 51.2 & 6.57 & 10.73 & 36.46 & 0.73 & 75.6 & 0.95 \\
PS & 63.4 & 7.75 & 17.60 & 35.12 & 0.72 & 80.0 & 0.40 \\
\hline
\end{tabular}

\subsection{The Effect of Surfaces on Tire/Road Noise}

Figure 3 presents the $L_{\mathrm{Amax}(1)}$ values at $60 \mathrm{kph}$ with accuracy measures, which is $95 \%$ confidence interval. Figure 4 shows differences in sound level on the studied surfaces in relation to the reference surface SMA11.

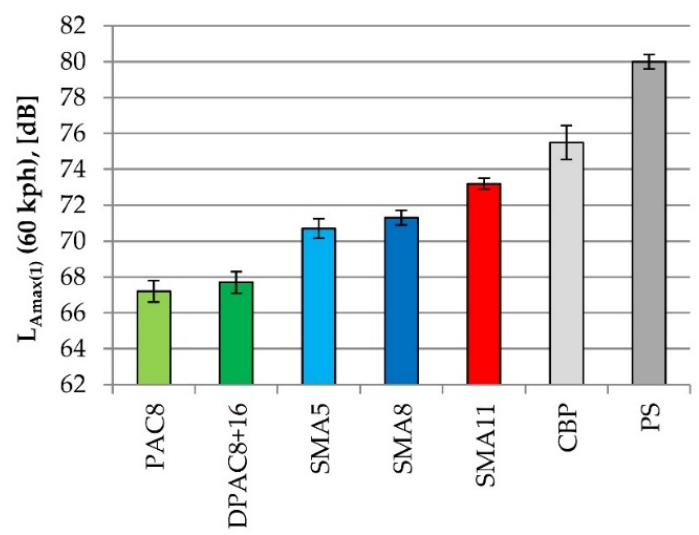

Figure 3. $L_{A \max (1)}$ with accuracy measure on tested surfaces. 


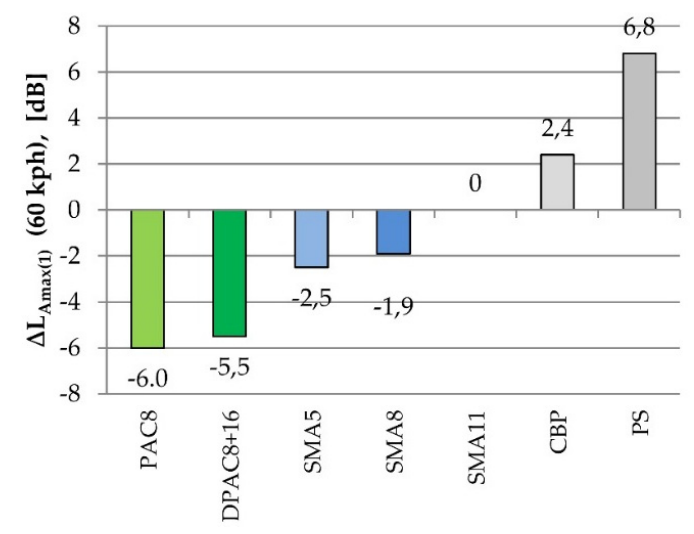

Figure 4. Differences between the values of noise level on tested surfaces in relation to the SMA11.

Presented values $L_{\mathrm{Amax}(1)}(60 \mathrm{kph})$ generated by the passing of a statistical car at a speed of $60 \mathrm{kph}$ confirm that the road surface has a significant impact on the level of noise, also in the range of low speeds. Paving stone surfaces are louder (by up to about $7 \mathrm{~dB}$ ) and porous asphalt surfaces quieter (even by up to $6 \mathrm{~dB}$ ) than the reference surface SMA11. The use of a smaller aggregate size in the stone mastic asphalt helps reduce the sound level by about $2 \mathrm{~dB}$. Such differences can be explained on the basis of sound spectra coming from a statistical car passing at a speed of $60 \mathrm{kph}$ (Figure 5).

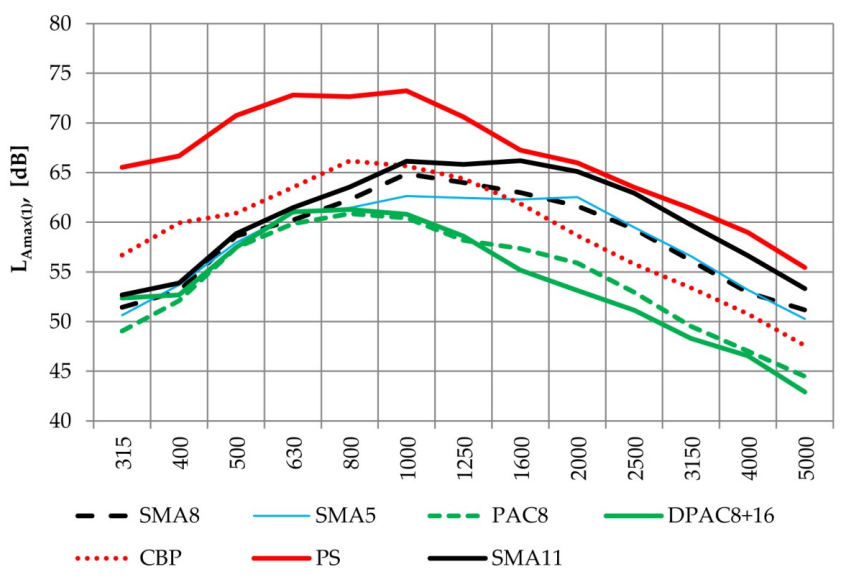

Figure 5. A-weighted frequency spectra in $1 / 3$ octave bands (SPB method, car, $V=60 \mathrm{kph}$ ).

In a range of studied frequency of $315-5000 \mathrm{~Hz}$, the paving stone is defined by the highest levels of sound. Due to increased air void content, porous asphalt surfaces are characterized by significantly lower levels of sound than stone mastic asphalt pavements in the frequency range above $800 \mathrm{~Hz}$. In the frequencies above $800 \mathrm{~Hz}$, higher sound levels were recorded on the surface of SMA11 than on those of SMA8 and SMA5. Concrete paving blocks, characterized by evenly spaced interlocking and a fine texture on the surface of individual blocks, contribute to higher sound level than the SMA and porous asphalt at frequencies lower than $1000 \mathrm{~Hz}$. Above the frequency of $1600 \mathrm{~Hz}$, sound level on this surface is lower than on surfaces finished with SMA, and higher than that of the porous asphalt.

\subsection{The Effects of Changes in the Speed of a Car on the Tire/Road Noise}

Taking into account the relations given in Table 1, the differences were determined regarding sound levels on the test sections, with an increase in speed of a car by $10 \mathrm{kph}, 20 \mathrm{kph}, 30 \mathrm{kph}$, and $40 \mathrm{kph}$ (in the range from $40 \mathrm{kph}$ to $80 \mathrm{kph}$ ) (Figure 6). The increase in the speed of vehicles by $10 \mathrm{kph}$ affects the increase in the maximum level of noise from a passing car by $2.6-3.6 \mathrm{~dB}$, with an increase in speed by $4.8-6.5 \mathrm{~dB}$ at $20 \mathrm{kph}$; at $30 \mathrm{kph}$, by $6.6-8.9 \mathrm{~dB}$; and, at $40 \mathrm{kph}$, by $8.1-11.0 \mathrm{~dB}$. 


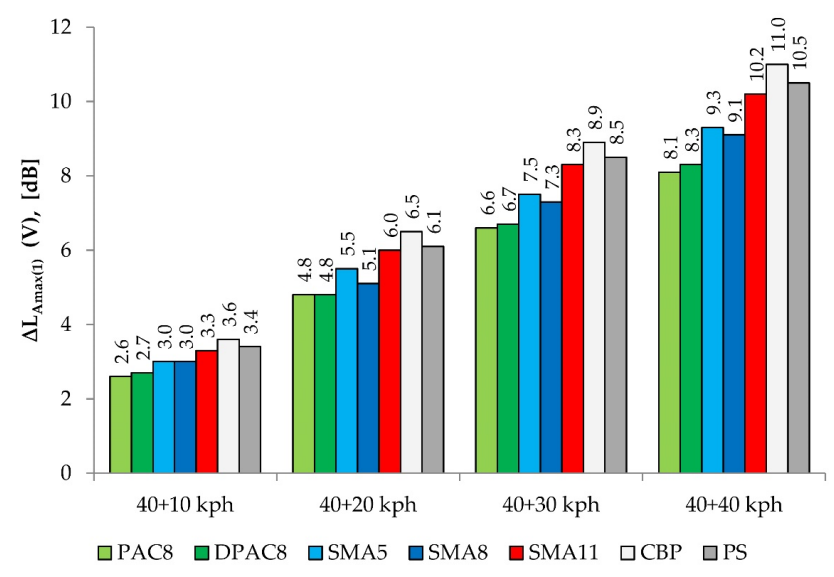

Figure 6. Differences between the values of noise level on tested surfaces in relation to the speed of vehicles.

The analysis of the data in Figure 6 shows that the increase in noise level with the raising of speed at a lower level (40-50 kph) is greater than in the case of the higher speed range recorded in the study (70-80 kph). For example, as the speed was raised from 40 to $50 \mathrm{kph}$, the noise level on the PAC 8 surface increased by $2.6 \mathrm{~dB}$, and, in the increase in speed from $70 \mathrm{kph}$ to $80 \mathrm{kph}$, by $1.5 \mathrm{~dB}$. The noise level on the PS surface changed by $3.4 \mathrm{~dB}$ and $2.0 \mathrm{~dB}$, respectively (Table 2).

Table 2. Differences between the values of noise level on PAC8 (in parenthesis: the values on paving stones) in relation to the speed of vehicles.

\begin{tabular}{|c|c|c|c|c|c|}
\hline Speed & $40 \mathrm{kph}$ & $50 \mathrm{kph}$ & $60 \mathrm{kph}$ & $70 \mathrm{kph}$ & $80 \mathrm{kph}$ \\
\hline $40 \mathrm{kph}$ & $x$ & $2.6(3.4)$ & $4.8(6.1)$ & $6.6(8.5)$ & $8.1(10.5)$ \\
\hline $50 \mathrm{kph}$ & - & $x$ & $2.2(2.7)$ & $4.0(5.1)$ & $5.5(7.1)$ \\
\hline $60 \mathrm{kph}$ & - & - & $x$ & $1.8(2.4)$ & $3.3(4.4)$ \\
\hline $70 \mathrm{kph}$ & - & - & - & $x$ & $1.5(2.0)$ \\
\hline $80 \mathrm{kph}$ & - & - & - & - & $x$ \\
\hline
\end{tabular}

\section{Lifetime Period of Porous Asphalt Surface and Tire/Road Noise}

In the case of surfaces with an increased air void content, a significant problem is posed by regular deterioration of acoustic properties during operation. The main reasons for this are surface clogging and locally occurring damages-potholes and loss of aggregate. An example of this would be the PAC8 surface of the road located in the rural area (Figure 7).

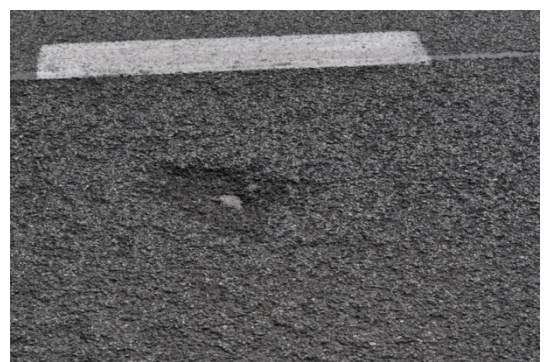

(a)

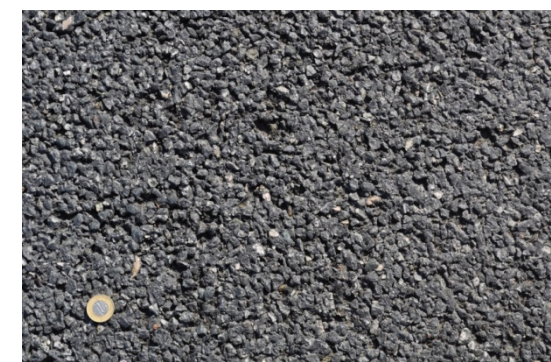

(b)

Figure 7. Example of damages on the PAC8 surface after 4 years of operation: (a) pothole; (b) loss of aggregate.

Figure 8 shows the results of testing on the surface of a porous asphalt PAC 8 in the first year and after two and four years of its operation, and Table 3 summarizes the results of the analysis. 


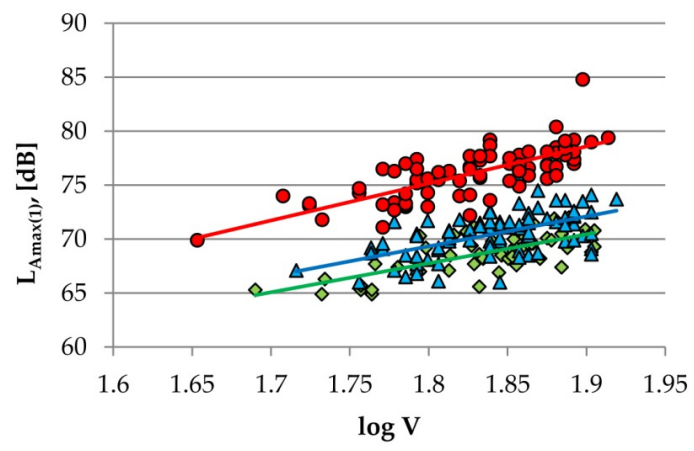

Figure 8. Results of SPB measurements on PAC8.

Table 3. Statistical information related to data SPB measurements on PAC8.

\begin{tabular}{ccccccc}
\hline Lifetime Period & $\boldsymbol{A}_{1}$ & $\boldsymbol{B}_{1}$ & $\boldsymbol{R}$ & $\boldsymbol{L}_{\text {Amax }}(\mathbf{5 0 )}$ & $\boldsymbol{L}_{\text {Amax }}(\mathbf{6 0 )}$ & $\boldsymbol{L}_{\text {Amax }}(\mathbf{7 0 )}$ \\
\hline PAC8-1 year & 19.36 & 26.89 & 0.71 & 65.0 & 67.2 & 69.0 \\
PAC8-2 years & 19.40 & 27.75 & 0.77 & 66.5 & 68.7 & 70.6 \\
PAC8-4 years & 13.40 & 34.29 & 0.75 & 71.7 & 74.4 & 76.7 \\
\hline
\end{tabular}

It was found that, within four years of operation, there has been a significant increase in the level of noise from the passing of a statistical car (by about $7 \mathrm{~dB}$ ). It should be noted here that a more significant increase was recorded within the higher range of vehicle speeds. The difference between the noise level in the first year and after four years was $6.7 \mathrm{~dB}$ for the speed of $50 \mathrm{kph}$, and $7.7 \mathrm{~dB}$ for $70 \mathrm{kph}$.

Spectral analysis of sounds (Figure 9) confirmed that the SMA11 above frequencies of $630 \mathrm{~Hz}$ is much louder than the surfaces of porous asphalt for up to two years of operation. Higher levels of sound at above $1000 \mathrm{~Hz}$ on the PAC8, after two years of service as compared to the levels determined in the first year of operation of the road, indicate a gradual clogging of this surface. Damages occurring on the PAC8 surface after four years of operation increase its macrotexture and create higher sound levels as compared with the levels of sound on the SMA11 in the frequency range of 500-1600 Hz. Lower levels of sound at frequencies above $1600 \mathrm{~Hz}$ recorded on the PAC8 surface, as compared to SMA11, confirm that despite some clogging and damage developing on it after four years of operation, PAC8 is still superior to a reference surface (SMA11) in terms of sound absorption.

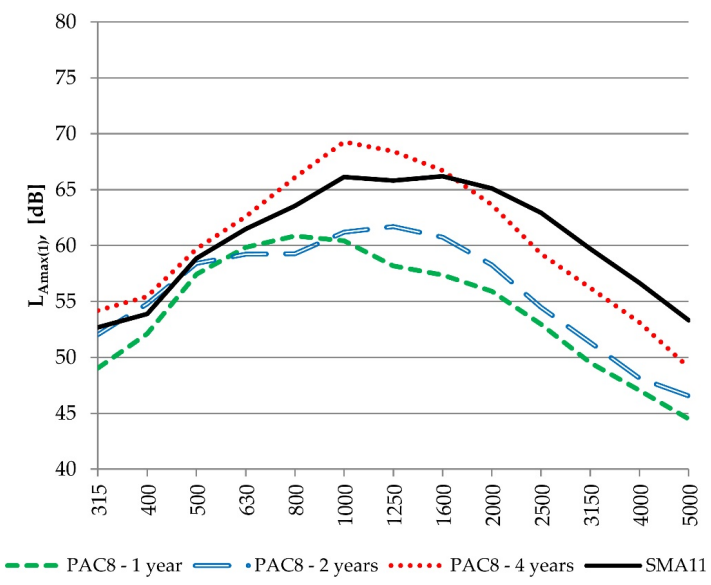

Figure 9. A-weighted frequency spectra in 1/3 octave bands on PAC 8 and SMA11 (SPB method, car, $V=60 \mathrm{kph})$. 


\section{Summary}

Roads and streets of lower speeds of passing vehicles are built both with standard asphalt pavements (AC and SMA), paving stones, concrete blocks paving, as well as low-noise surfaces (porous asphalt, thin asphalt layers). Noise level measurements conducted by using the SPB method on vehicles passing at $60 \mathrm{kph}$ have shown that paving stones surfaces are louder by $6.8 \mathrm{~dB}$ in comparison to SMA11. Surfaces with reduced noise (PAC and DPAC) are quieter by 5.5-6.0 dB than the reference surface SMA11. Maximum aggregate size is a very significant feature in the stone mastics asphalt; its reduction from $11 \mathrm{~mm}$ to $5 \mathrm{~mm}$ decreases the sound level of a car by $2.5 \mathrm{~dB}$.

It was discovered that increasing the speed of a car by $10 \mathrm{kph}$ (from 40 to $50 \mathrm{kph}$ ) contributes to the increase in noise level from $2.6 \mathrm{~dB}$ to $3.6 \mathrm{~dB}$. These differences are much greater (from $8.1 \mathrm{~dB}$ to $11.0 \mathrm{~dB}$ ) when increasing speed by $40 \mathrm{kph}$. It was also found that the increase in the noise level at the speed of $40-50 \mathrm{kph}$ is greater than at higher speeds.

Moreover, it was also demonstrated on the example of porous asphalt that clogging development during operation and local damages on the surface (potholes, loss of aggregate) decisively deteriorate its acoustic properties. After four years of operation, the PAC8 demonstrated a higher level of tire/road noise than a SMA11.

Acknowledgments: The study have been carried out in the framework of project No. S/WBiIS/2/2010 and S/WBiIS/1/2015 at Bialystok University of Technology funded by Polish Ministry of Science and Higher Education.

Author Contributions: Experimental measurements have been conducted by all the co-authors. The analysis and interpretation of the results as well as conclusions have been conducted by Wladyslaw Gardziejczyk. The manuscript has been written by all the co-authors.

Conflicts of Interest: The authors declare no conflict of interest.

\section{References}

1. Abbott, P.G.; Morgan, P.A.; McKell, B. A Review of Current Research on Road Surface Noise Reduction Techniques; Transport Research Laboratory: Wokingham, UK, 2010.

2. Morgan, P.A.; Stait, R.E.; Reeves, S.; Clifton, M. The Feasibility of Using Twin-Layer Porous Asphalt Surfaces on England's Strategic Road Network; Transport Research Laboratory: Wokingham, UK, 2007.

3. Sandberg, U.; Mioduszewski, P. The importance for noise reduction of the bottom layer in double-layer porous asphalt. J. Acoust. Soc. Am. 2012, 131. [CrossRef]

4. Sandberg, U.; Goubert, L. PERSUADE-A European project for exceptional noise reduction by means of poroelastic road surfaces. In Proceedings of the 40th International Congress and Exposition on Noise Control Engineering 2011 (INTER-NOISE 2011), Osaka, Japan, 4-7 September 2011.

5. Ejsmont, J.A.; Sandberg, U.; Świeczko-Żurek, B.; Mioduszewski, P. Tyre/road noise reduction by a poroelastic road surface. In Proceedings of the 43rd International Congress on Noise Control Engineering 2014 (INTER-NOISE 2014), Melbourne, Australia, 16-19 November 2014.

6. Freitas, E.F. The effect of time on the contribution of asphalt rubber mixtures to noise abatement. Noise Control Eng. J. 2012, 60, 1-8. [CrossRef]

7. Licitra, G.; Cerchiai, M.; Teti, L.; Ascari, E.; Fredianelli, L. Durability and variability of the acoustical performance of rubberized road surfaces. Appl. Acoust. 2015, 94, 20-28. [CrossRef]

8. Sandberg, U.; Ejsmont, J.A. Tyre/Road Noise. Reference Book; Informex: Kisa, Sweden, 2002.

9. Gardziejczyk, W. Influence of road pavement macrotexture on tyre/road noise of vehicles. Baltic J. Road Bridge Eng. 2014, 9, 182-192. [CrossRef]

10. Anfosso-Lédée, F.; Brosseaud, Y. Acoustic monitoring of low noise road pavements. Noise Control Eng. J. 2009, 57, 50-62. [CrossRef]

11. Bendtsen, H.; Kohler, E.; Lu, Q.; Rymer, B. California-Denmark study on acoustic aging of road pavements. Transp. Res. Record 2010, 2158, 122-128. [CrossRef]

12. Bendtsen, H.; Andersen, B.; Oddershede, J.; Iversen, L.M. Long time effect of noise reducing thin layer pavements. In Proceedings of the 41st International Congress and Exposition on Noise Control Engineering 2012 (INTER-NOISE 2012), New York, NY, USA, 19-22 August 2012. 
13. Mioduszewski, P.; Gardziejczyk, W. Noise measurements on low noise pavements-Problems with inhomogeneity of wearing course. In Proceedings of the 42nd International Congress and Exposition on Noise Control Engineering 2013 (INTER-NOISE 2013), Innsbruck, Austria, 15-18 September 2013.

14. Gardziejczyk, W. The effect of time on acoustic durability of low noise pavements-The case studies in Poland. Transp. Res. Part D Transp. Environ. 2016, 44, 93-104. [CrossRef]

15. Anfosso-Lédée, F.; Pichaud, Y. Temperature effect on tyre-road noise. Appl. Acoust. 2007, 68, 1-16. [CrossRef]

16. Berge, T.; Storeheier, S.A.. Low noise pavements in a Nordic climate. Results from a four year project in Norway. In Proceedings of the 38th International Congress and Exposition on Noise Control Engineering 2009 (INTER NOISE 2009), Ottawa, ON, Canada, 23-26 August 2009.

17. Gardziejczyk, W. Comparison of vehicle noise on dry and wet road surfaces. Found. Civ. Environ. Eng. 2007, 9, 5-20.

18. Miljković, M.; Radenberg, M. Thin noise-reducing asphalt pavements for urban areas in Germany. Int. J. Pavement Eng. 2011, 13, 569-578. [CrossRef]

19. Paje, S.E.; Bueno, M.; Terán, F.; Viñuela, U.; Luong, J. Assessment of asphalt concrete acoustic performance in urban streets. J. Acoust. Soc. Am. 2008, 123, 1439-1445. [CrossRef] [PubMed]

20. ISO 11819-1 Acoustics-Method for Measuring the Influence of Road Surfaces on Traffic Noise-Part 1: The Statistical Pass-By Method; ISO: Geneva, Switzerland, 1997.

(C) 2016 by the authors; licensee MDPI, Basel, Switzerland. This article is an open access article distributed under the terms and conditions of the Creative Commons by Attribution (CC-BY) license (http://creativecommons.org/licenses/by/4.0/). 